\title{
Effect of Process Parameter Variation on Purity during Rotary Fractional Crystallization of Aluminum
}

\author{
Semiramis Friedrich*, Danilo Coladetti Curtolo, Bernd Friedrich \\ IME Process Metallurgy and Metal Recycling, RWTH Aachen University, Aachen, Germany \\ Email: *SFriedrich@ime-aachen.de
}

How to cite this paper: Friedrich, S., Curtolo, D.C. and Friedrich, B. (2017) Effect of Process Parameter Variation on Purity during Rotary Fractional Crystallization of Aluminum. Open Journal of Metal, 7, 2538.

https://doi.org/10.4236/ojmetal.2017.72003

Received: April 3, 2017

Accepted: June 17, 2017

Published: June 20, 2017

Copyright $\odot 2017$ by authors and Scientific Research Publishing Inc. This work is licensed under the Creative Commons Attribution International License (CC BY 4.0).

http://creativecommons.org/licenses/by/4.0/

\begin{abstract}
High pure and ultrapure Aluminum is increasingly used in highly corrosion resistant applications or to replace copper in conductive parts such as high voltage cable and transformers due to their higher electrical conductivity properties. Ultrapure Aluminum is also used in semiconductors industry. Hence, the market demands innovative refining technologies, which consume less energy, take less time and lead to higher resource efficiencies. The most common methodology to produce ultrapure Aluminum is zone refining, based on the principle of fractional crystallization. Zone refining is however a very time-consuming process. In order to achieve a purity of $6 \mathrm{~N}$, several passes along the crucible with each full day treatment must be carried out. Also this method cannot be conducted continuously. This paper presents first time a new and eco-efficient method, which offers high potential to meet the mentioned multi-dimensional demands. Firstly, distribution coefficients of main impurities in Aluminum-a deciding factor to forecast and assess the removal behavior of impurities-were studied theoretically as a function of temperature using thermo-chemical calculation in FactSage ${ }^{\mathrm{TM}}$. Secondly, the innovative method using a rotating and gas cooled crystallizer ("cooled finger") was developed to validate the principle. The influencing process parameters such as temperature gradient, cooling gas flow rate, etc. were experimentally investigated and the theoretical results could be verified.
\end{abstract}

\section{Keywords}

Fractional Crystallization, Aluminum, High Purity, Distribution Coefficient, Temperature Gradient, Cooled Finger, FactSage, Burton-Prim-Slichter Model

\section{Introduction}

Fractional crystallization principle: fractional crystallization is the crucial pro- 
cess for ultra-purity refining of metals and metalloids. Crystallization from the melt has the great advantage of high selectivity in comparison to other pyrometallurgical melting processes. Thereby, distribution of impurities during the phase transition liquid/solid is used for refining of the initial metal as well as for doping of accompanying elements (e.g. to produce extrinsic semiconductors). An important parameter for impurity distribution in the target metal is the distribution coefficient (see Figure 1), which describes the ability to separate the different components in the melt [1] [2]. To remove unwanted elements from the target metal, the solubility of the impurities in the melt and in the crystal must be different. The distribution coefficient $k$ is generally defined (Formula (1)) as the ratio of the concentration of an element in the solid phase $\left(C_{S}\right) \mathrm{di}$ vided by the concentration in the liquid phase $\left(C_{L}\right)$.

$$
k=\frac{C_{S}}{C_{L}}
$$

$k$-Distribution coefficient; $C_{S}$-concentration in solid; $C_{L}$-concentration in liquid.

Here, the distribution coefficient of any chemical composition is depending on thermo-dynamical properties of components, kinetics on the interface liquid/ solid, diffusion and convection on the phase boundary [3] [4]. The distribution coefficient can take values smaller or bigger than one. Elements with $k$-values of $<1$ decrease the melting point and have a limited solubility in the target metal (Figure 1 upper right). If the distribution value $k \ll 1$ (for example, 0.01), the solubility in the target metal is extremely low, thereby a separation by fractional crystallization principle can be realized very well. If the k-value is greater than one, however, not only the melting temperature of the target metal is increased but also the impurities concentrate itself on the crystallized solid [5] [6].

The crystallization is, among other factors, greatly influenced by the undercooling effect on the growth layer at the liquid-solid interface, which can be represented by the equation 2 below [6] [7] [8].
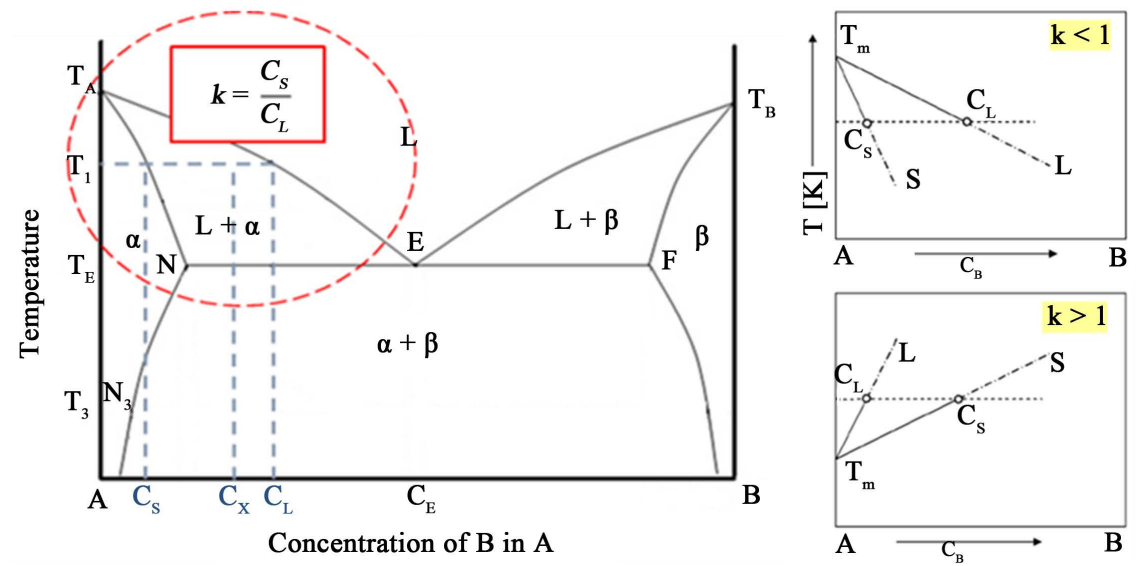

Figure 1. (Left) an exemplary binary phase diagram illustrating the calculation of distribution coefficient and (right) the influence of distribution coefficient on the melting temperature [9]. 


$$
\frac{G}{\Delta T} \leq \frac{D \cdot k}{m \cdot C_{0} *(1-k)}
$$

where $\Delta T$ is the temperature gradient in the liquid interface, $G$ is growth rate, $m$ is the slope of liquidus line in the phase diagram, $k$ is the distribution coefficient $\left[C_{s} / C_{L}\right.$ ], $D$ is the impurity diffusivity in the melt and $C_{0}$ is the initial concentration.

For a better segregation, one should keep the growth rate at low levels, allowing this Kinetic-driven process to occur. Process parameter like furnace temperature, mixing degree and cooling gas flow rate can indirectly control the temperature gradient in the process and as well as the growth rate. Those will eventually be indirectly correlated to the segregation effectiveness of the process. As the growth rate increases to a level higher than the rate of solute rejection, an increase in the k-value should be observed.

Innovative methodology "rotational immersing cooled finger": The process to be studied in this paper is based on an internally cooled crystallization unit (socalled "cooled finger"), which is rotationally immersed into the molten Aluminum. Although this idea was patented 1982 in Japan (see Figure 2), until today neither scientific detail has been published nor the process been fundamentally investigated [10].

This is more remarkable, because all purification methods currently available are distinguished by complex technical systems and low efficiency. For example, while zone refining requires several passes with each taking a full day in order to improve the metal just to one purity-grade (reduction of foreign metals of a factor of 10) higher. According to Figure 2 the rotation is in correlation with a low temperature gradient between the melt and the "cooled finger" and the released crystallization heat causes a controlled metal layer deposition. The goal is a smooth-walled solidification without dendrite formation, in whose interspace melt could be entrapped. Via this concept, it should be possible to increase the purity from an initial $99.99 \%$ to at least $99.9995 \%$ in only one step [9].

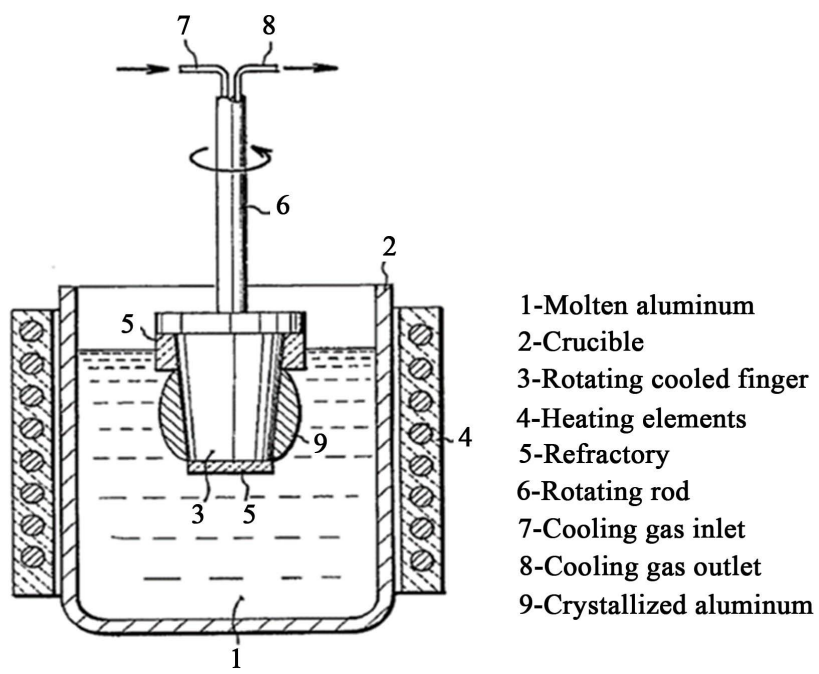

Figure 2. Principle of cooled finger crystallization concept [10]. 


\section{Assessment Methodology and Experimental Procedure}

The distribution coefficient of four common impurities in Aluminum, i.e. Iron, Silicon, Nickel and Lead have been preliminary modeled via the thermo -chemical software FactSage ${ }^{\mathrm{Tw}}$, (using the database Ftlite). The data of the solid and liquid lines, gathered from each binary phase diagram $\mathrm{Al}-\mathrm{X}$, were converted to a polynomial equation of $C_{X, S}=f(T)$, respectively $C_{X, L}=F(T)$, in which $C_{X}$ is the concentration of Element $\mathrm{X}$ in solidus or liquidus line and $\mathrm{T}$ the temperature. Based on these equations, the concentration of each impurity element in liquidus resp. solidus line and at different temperatures were calculated. Using Equation (1) the distribution coefficient of Element $\mathrm{X}$ was then calculated as a function of temperature as well.

Parallel to the theoretical studies a series of experimental trials were applied to investigate practical feasibility of the concept, namely the temperature gradient, crystallization temperature as well as growth rate. For this procedure an innovative setup including a rotational cooled hollow rod made of steel covered with high purity graphite was designed and installed, illustrated in Figure 3. This "cooled finger" has a diameter of $30 \mathrm{~mm}$ and active length (the length immersing into the molten bath) of $160 \mathrm{~mm}$. Compressed air was selected as the cooling medium inserting from top of the system, distributing inside the steel rod and then rejected out without having contact to the liquid Aluminum. The crucible applied in this process also made of graphite has a conical form with an upper internal diameter of $160 \mathrm{~mm}$, lower internal diameter of $100 \mathrm{~mm}$ and the length of $200 \mathrm{~mm}$ (from which $180 \mathrm{~mm}$ is the active length).

The cooled finger is able to rotate inside the melt via an electrical motor with variable rpms. This allowed to adjust an appropriate mixing inside the bath and

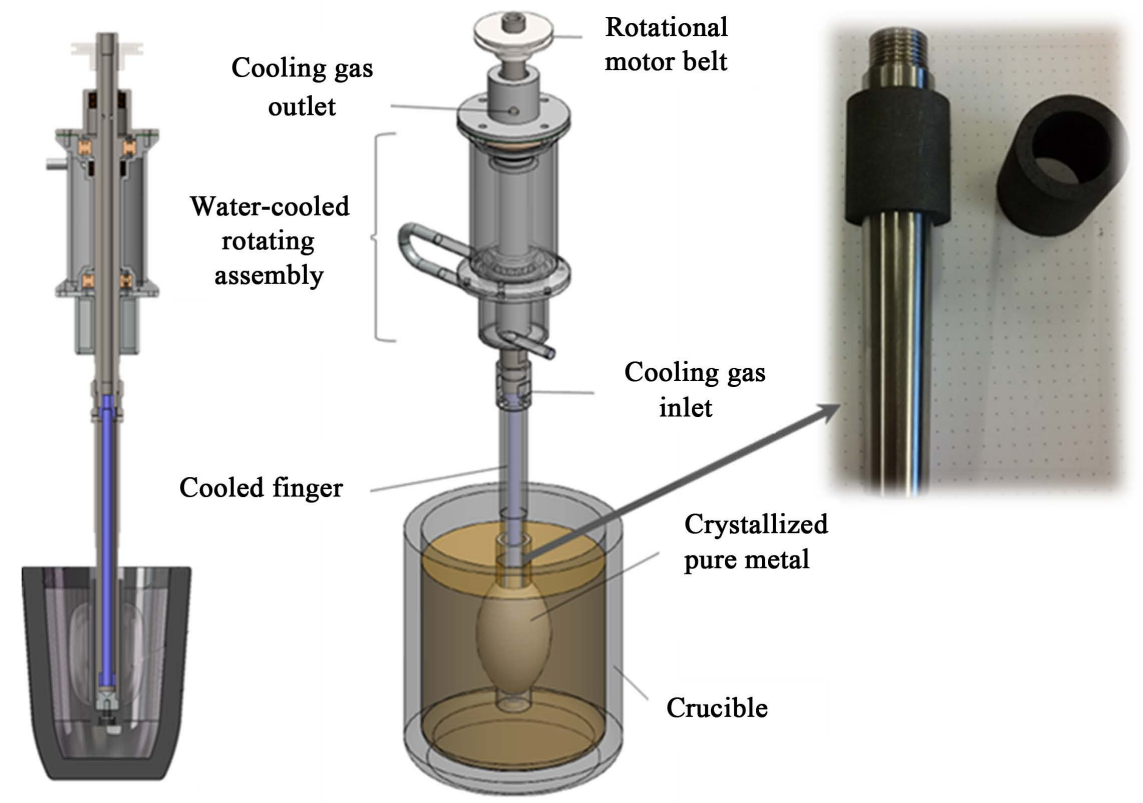

Figure 3. (middle) experimental apparatus of crystallization including "cooled finger" and rotational system, (left) a cross section of the whole unit and (right) steel "cooled finger" with graphite shell. 
ensure small diffusion layers. In order to avoid the driving system becoming too hot, this is cooled indirectly with water (see Figure 3, middle). For those experiments, in which only the temperature gradient was investigated, the temperature was measured both inside the graphite shell of "cooled finger" as well as inside the molten bath beside the crucible's wall. In that case, no rotation was be used.

\section{Results and Discussion}

Before calculating the theoretical or experimental distribution coefficient, the two important terms controlling crystallization, i.e. temperature gradient and crystallization temperature were determined.

Experimentally measured temperature gradient: As illustrated in Figure 4, the crystallized material grows continuously. According to the final thickness of this layer and with knowing the molten bath diameter (crucible diameter), the growth during this crystallization per unit of time can be measured. Therefore, for every moment of time (ti) the distance from the crystallization front to the crucible wall ( $\delta \mathrm{xi})$ can be estimated. In addition, the ever-changing temperature difference between the crystallized front and the melt beside the wall $(\Delta \mathrm{Ti})$ can be experimentally obtained (see Figure 4), allowing for the temperature gradient to be calculated as a function of time $(\Delta \mathrm{T} / \delta \mathrm{x})$.

\section{Melt $\left(\mathrm{T}_{1}\right) \quad$ Cooled Finger $\left(\mathrm{T}_{2}\right)$}

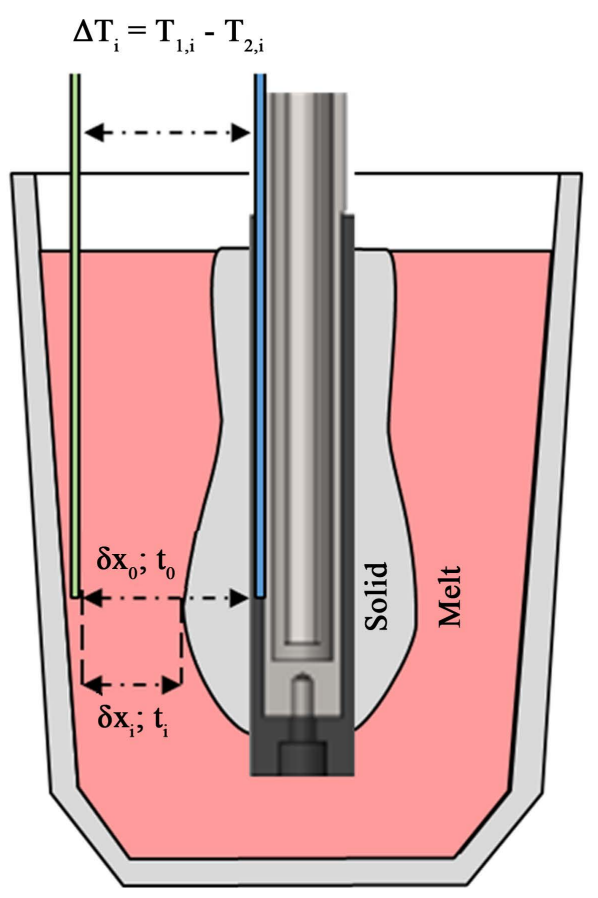

Figure 4. Schematic illustration of Cooled Finger experimental setup, where $t_{i}$ is the every moment of time, $\delta \mathrm{x}_{\mathrm{i}}$ the ever-changing distance between crystallization front and the crucible wall and $\Delta \mathrm{T}_{\mathrm{i}}$ the ever-changing temperature difference between the crystallized front and the melt beside the wall. 
We assume in this preliminary study, that the temperature of the crystallization front is more or less the same as the temperature inside the "cooled finger" (due to the fact of very good heat conductivity of Graphite and $\mathrm{Al}$ and particularly because it is very difficult to measure the temperature while growing the front). Hence, in this experimental setup, the thermo-elements were placed inside the graphite shell $\left(T_{2}\right)$ and adjacent to the crucible wall $\left(T_{1}\right)$ at the same depth in the molten bath. The temperature profile was then recorded during the trials. Consequently, these trials were conducted without rotation due to the thermocouple wires attached to the equipment.

With the two parameters of $\Delta \mathrm{T}$ and $\delta \mathrm{x}$ the temperature gradient $(\Delta \mathrm{T} / \delta \mathrm{x})$ will be approximated as well. Figure 5 illustrates the temperature gradient for three different cooling gas flow rates. With a very high cooling gas flow rate (e.g. 70 $\mathrm{L} / \mathrm{min}$ ), higher growth velocity was observed. While for the lowest one (45 $\mathrm{L} / \mathrm{min}$ ), the metal solid crystal could not be grown as a layer over the cooled finger wall, but rather homogeneously distributed within the melt in a mushy form (quite like a rapid solidification case). The absence of growth layer, when using much lower cooling rates, is due to the lack of sufficient thermal gradient between the melt and the cold surface of the Cooled Finger resulting in a de-attached growth of the formed crystals.

By comparison, the trial with e.g. $50 \mathrm{~L} / \mathrm{min}$ proved to have optimum conditions to achieve a stable growth rate as well as induce the solute segregation and enable the adhesion of a solid layer on the "cooled finger" surface (see the collected products for each curve in Figure 5).

Crystallization temperature: Figure 6 shows the temperature profile of the bulk molten metal bath in a period of time. As it is seen, it takes between some minutes to one hour after immersion of "cooled finger" to achieve a stable level of (start-) temperature. When immersed into the melt, the "cooled finger" system extracts heat by constantly dropping the melt temperature until it reaches

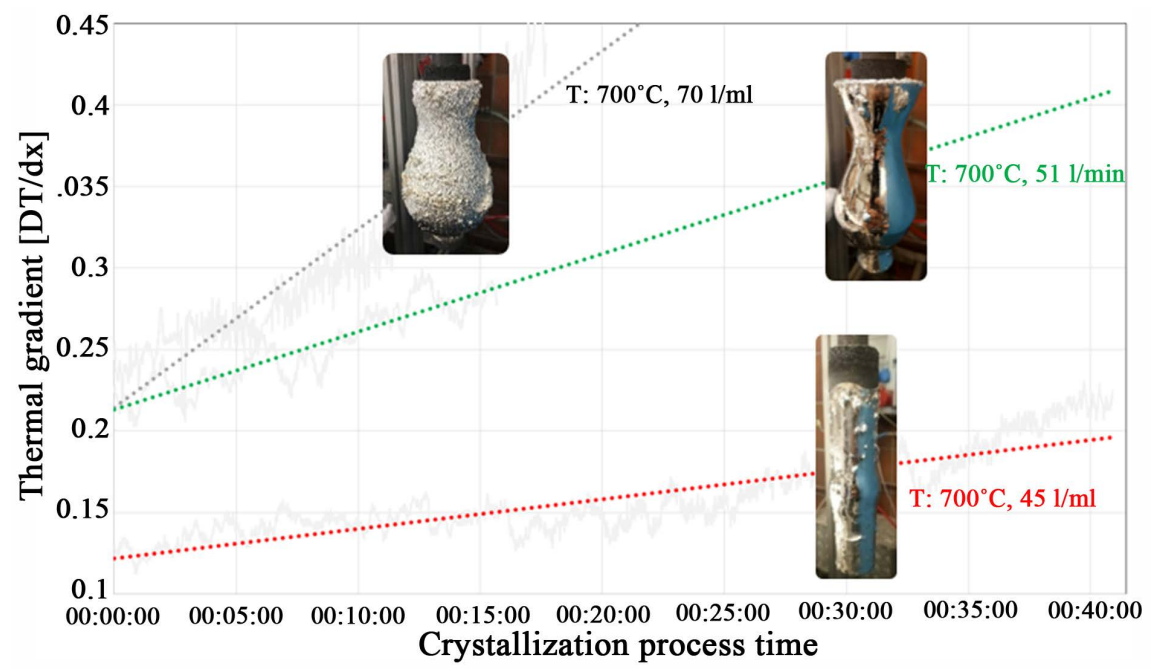

Figure 5. The experimental temperature gradient between the molten bath and the "cooled finger" according to the Process Parameters Melt Temp $\left[{ }^{\circ} \mathrm{C}\right]$ as well as cooling gas flow rate $(\mathrm{L} / \mathrm{min})$. 


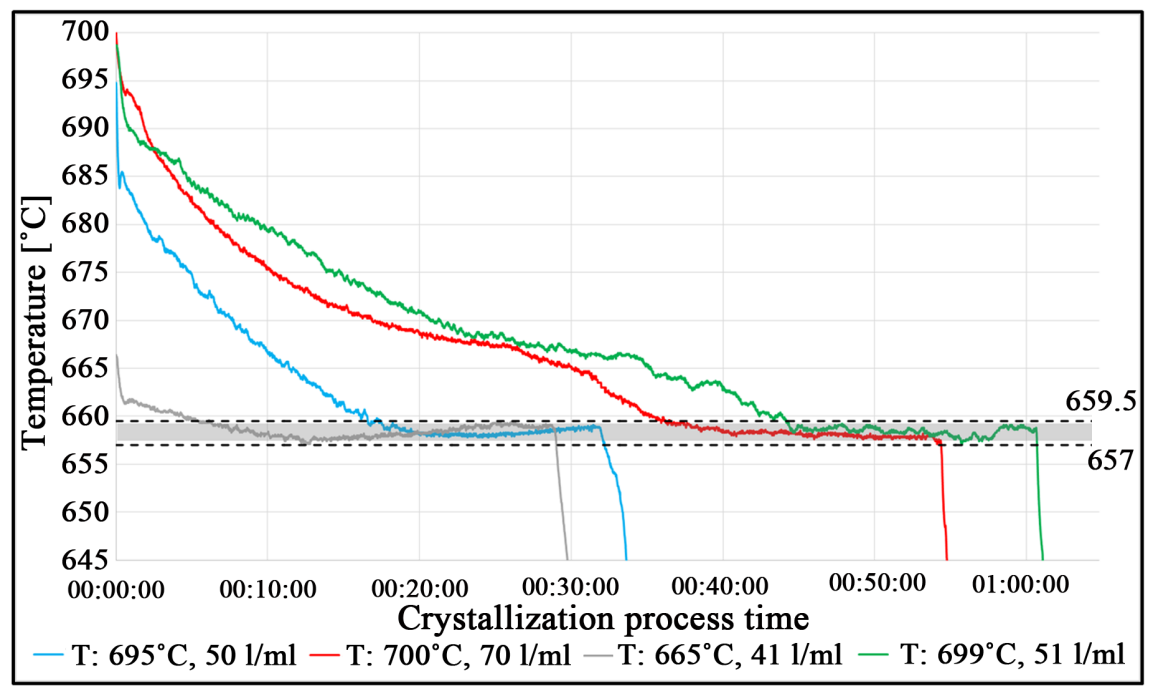

Figure 6. The experimental profile of the crystallization temperature at different initial melt, initial temperature and different cooling gas flow rate without rotation of the "cooled finger".

the crystallization temperature range, where from this point, latent heat is extracted and through an undercooling effect the growth is induced on the coldest region e.g. "cooled finger" surface.

The duration to achieve this stable level is depending on the cooling effect of the finger, influencing by cooling gas flow rates, cooling surface and finger dimensions, diameter of the crucible/molten bath, rotation, etc. In these series of experiments, the initial temperature of the molten bath as well as the cooling gas flow rate were taken as the variable parameters. However, in all these different operational situations, the stable temperature (crystallization temp.) remains with $\pm 2^{\circ} \mathrm{C}$ the same (see Figure 6, the grey region). This temperature region is between $657^{\circ} \mathrm{C}-659.5^{\circ} \mathrm{C}$ very shortly below the liquidus temperature.

As the process starts, the temperature of the melt $\left(\mathrm{T}_{1}\right)$ is constantly dropped by the inlet gas flow inside the Cooled Finger until it reaches a "plateau" (see the gray area), where the extracted heat from the system induces the crystallization of the melt over the colder surface of the Cooled Finger. From now on, the $\mathrm{T}_{1}$ remains relatively constant until the end of the experiment or until there is no more molten metal to be crystallized. Hence, for any initial conditions or cooling rate, the crystallization temperature will be the same but also depends on the liquidus temperature of applied metallic system. It should be though mentioned that crystallization rate is influenced by convection and agitation/mixing through rotation mechanism as well.

For the current system (Al), the Green line (starting $\mathrm{T}_{1}=700^{\circ} \mathrm{C}$, cooling gas flow rate $=50 \mathrm{~L} / \mathrm{min}$ ), demonstrates a better stability to achieve the gray plateau without generating too much cooling effect while keeping a satisfactory growth rate. That all will result a good solute segregation.

Chemical analysis through spark spectrometry showed e.g. in two cases of green $\left(699^{\circ} \mathrm{C}, 50 \mathrm{~L} / \mathrm{min}\right)$ and $\mathrm{red}\left(700^{\circ} \mathrm{C}, 70 \mathrm{~L} / \mathrm{min}\right)$ lines, significant differences 
about the removal percentages of iron and silicon impurities. The process parameters of the green line caused about $60 \% \mathrm{Si}$ - as well as $50 \% \mathrm{Fe}$-removal in comparison with only $11 \% \mathrm{Si}$ - and $28 \% \mathrm{Fe}$-removal through the parameters of red line. It should though be noticed-as mentioned before-that the results of this figure were gathered without using any rotation in the "cooled finger". The effect of rotation (presented in Figure 7) induces a better temperature distribution across the melt, reducing the temperature gradient as well as allowing lower growth rates by mixing the temperature of the surrounding region. Additionally, the resulting melt flow adjacent to the crystallization front will assist in the dissolution of segregated solute into the bulk melt, promoting a lower concentration gradient and facilitating the fractional crystallization to occur in a more effective way. This huge effect of rotating to decrease the diffusion layer can make an expectation of even higher impurities removal efficiencies than that mentioned above. The Figure 7 represents the significant difference between two trials with the identic operational parameters, but one with and one without rotation. However, in these series of preliminary experiments, the effect of rotation has not been investigated deeply.

The control of growth rate, either by the cooling gas flow rate itself or in conjunction with rotation, will promote a stable growth front, in which the impurities will be segregated from the base metal towards the liquid phase. In the case of multi-crystalline growth during the process, those impurities, which cannot migrate to the solid/liquid interface and therefore not be expelled to the adjacent liquid phase, will be precipitated on the grain boundary of the crystallized material. Figure 8 illustrates $\mathrm{Fe}$-and Si-enriched region on the grain boundary
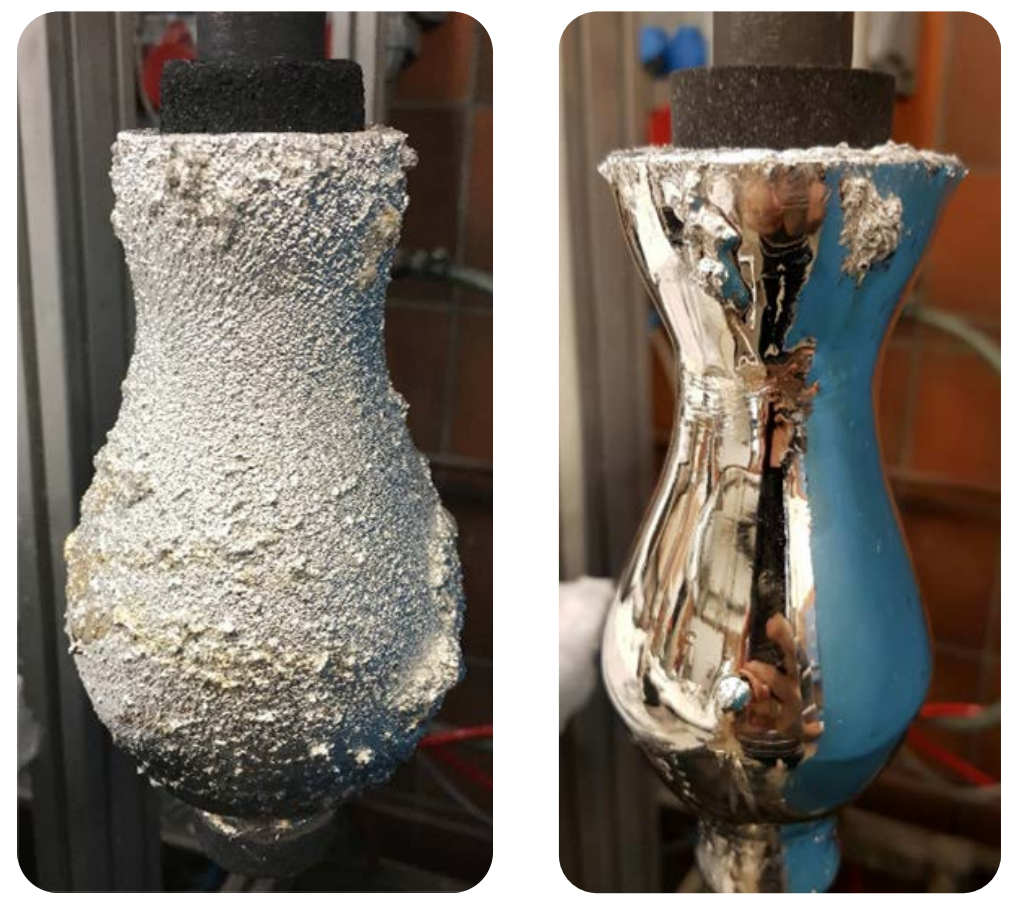

Figure 7. The difference on the crystallization surface between an experiment without (left) and with (right) rotation. 


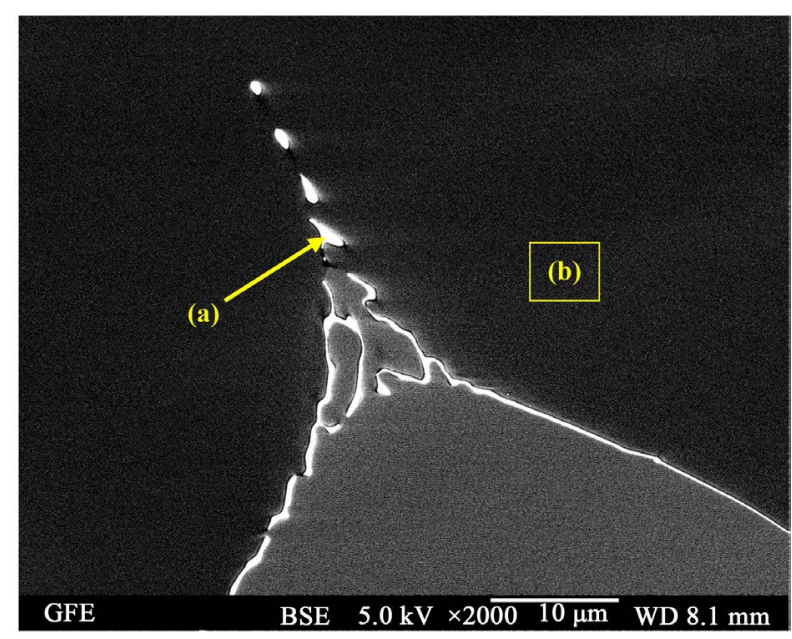

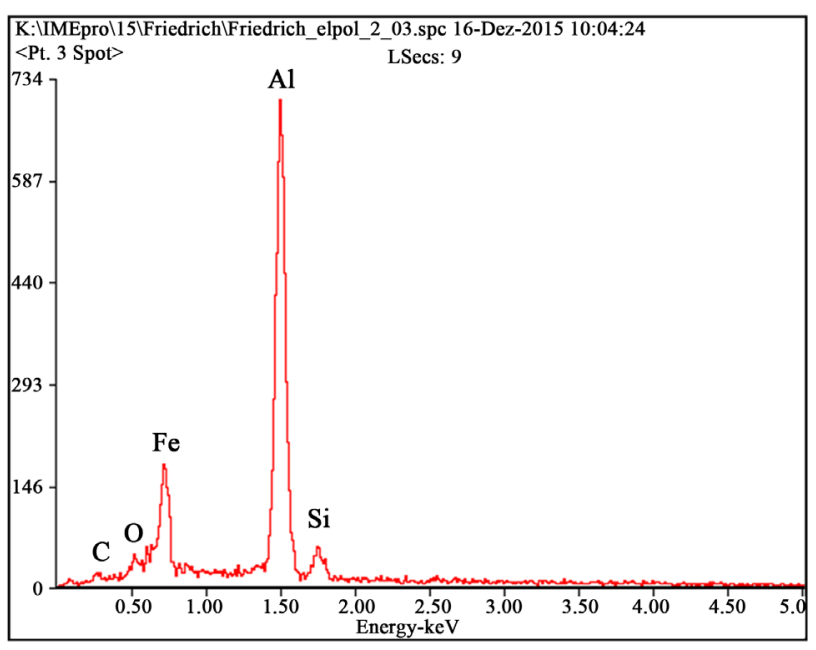

(a)

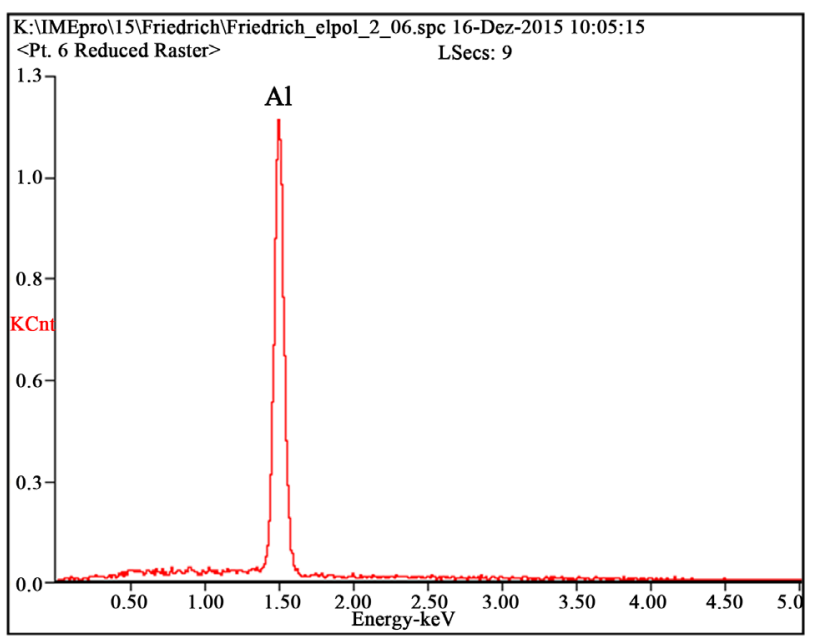

(b)

Figure 8. SEM-(top) and EDX-(middle and bottom) pattern of a sample of crystallized Aluminum containing $\mathrm{Si}$ and Fe as main impurities, performed via cooled finger methodology.

(showed in region A) compared to the grain surface (Region B) as a SEM-EDX analyses pattern. The lighter gray region has the same results showed in region $B$, only with different grain orientation. The existence of carbon and oxygen traces in these patterns could be because of the oxidization of Aluminum while processing as well as external contaminations through graphite crucible.

Calculation of distribution coefficient: The distribution coefficient as a function of temperature was calculated in Fact Sage, using the individual binary phase diagram of each system (Al-X) as well as using the Equation (1). The $X_{S}$ and $X_{L}$ in the binary phase diagrams developed in Fact Sage were defined as a polynomial function of temperature as $X=a T^{3}+b T^{2}+c T+d$ with a $\mathrm{R}^{2} \sim 0.99999$. Using the individual constant factors for each equation at a specific temperature, $X_{S}$ and $X_{L}$ were calculated for values of temperature until the eutectic point. Using Equation (1) the distribution coefficient is calculated as $k=\frac{X_{S}}{X_{L}}$ and represented in Figure 9. This coefficient is only valid if a complete mixing 


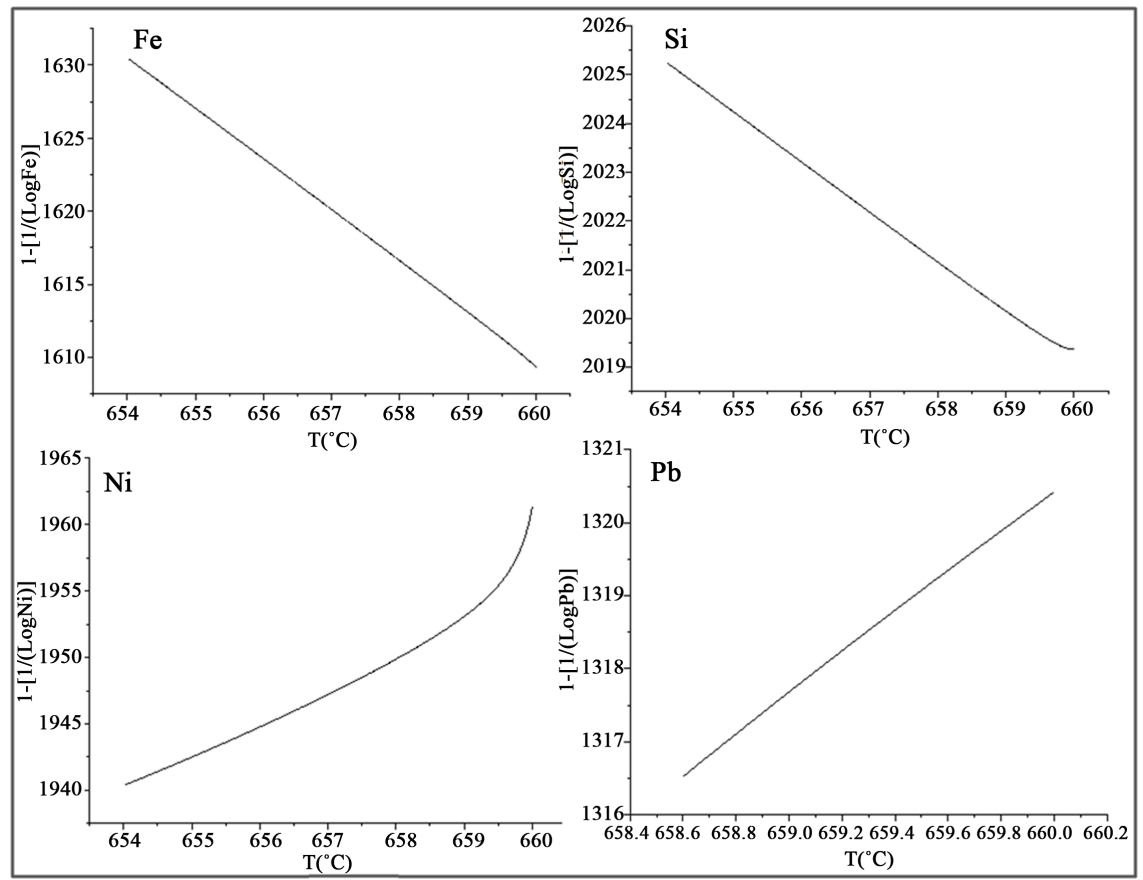

Figure 9. Distribution coefficient of the most common Aluminum impurities versus temperature in the case of a complete mixing, calculated through FactSage.

in the liquid is assumed (ideal system). Here the different tendencies of distribution coefficient in dependence of temperature for different impurities have been illustrated. This figure shows that in contrast to iron, silicon, whose coefficients decrease due to the temperature rising, some impurities such as lead and nickel show an increasing pace with temperature. That means finding an appropriate crystallization temperature to remove all these impurities simultaneously would be a challenge. Though, according to Figure 8 , these values still remain $<<1$, and even lower that of the iron, silicon and zinc at the same temperature.

Experimental-based distribution coefficient and comparison with FactSage-calculation: Generally for a non-ideal system with partial mixing in the liquid, the effective distribution coefficient based on BPS (Burton-Prim-Slichter) should be considered (see Equation (3)) [11] [12].

$$
k_{\text {eff }}=\frac{C_{S}}{C_{L}}=\frac{k_{0}}{k_{0}+\left(1-k_{0}\right) \mathrm{e}^{\frac{G \delta}{D}}} \rightarrow \ln \left(\frac{1}{k_{\text {eff }}}-1\right)=\ln \left(\frac{1}{k_{0}}-1\right)-\frac{G \delta}{D}
$$

In which $C_{S}$ and $C_{L}$ are the experimental values for the impurity concentration in solid as well as in liquid (e.g. here chemically analyzed through spark spectrometric method), $k_{0}$ is the equilibrium distribution coefficient, $G$ the growth/solidification rate of the crystallization front, $D$ the diffusion coefficient of each impurity in $\mathrm{Al}$ and $\delta$ is the diffusion layer thickness.

Using the experimental results and the chemical analysis of the products, $k_{\text {eff }}$ can be calculated as $k_{\text {eff }}=\frac{C_{\text {on cold finger }}}{C_{\text {crucible residue }}}$. That means, $C_{S}$ is in this case the concentration of the impurity in already crystallized material and $C_{L}$ is the concen- 
tration of the same impurity remained in the molten phase (crucible residue). On the other hand, the solidification velocity $(G)$ for different trials can be calculated through measuring the thickness of the crystallized material over the known period of dwelling time (as micron/sec). With the help of these two known variables ( $k_{\text {eff }}$ and $G$ ), the trend line of $y=A x+B$ can be drown, where $y$ is the $k_{\text {eff }} x$ is the $G, A$ (slope) is $-\delta / D$ and $B$ (intercept) is $\ln \left(1 / k_{0}^{\prime}-1\right)$. From this trend line, the $k_{0}^{\prime}$-the empirical values of distribution coefficient-can be evaluated for each impurity and compared to the theoretical value from FactSage.

The solidified material of these "proof of principle experiments" was analyzed chemically via spark spectrometry measurement device, whose results have been illustrated in Figure 10. In this diagram the concentrations of the most important impurities ( $\mathrm{Fe}, \mathrm{Si}, \mathrm{Pb}$ and $\mathrm{Ni}$ ) before and after the crystallization process using "cooled finger" have been compared by so called reduction factor at three temperature intervals. Reduction factor is defined as the ratio of concentration on the "cooled finger" to the initial one, subtracted from 100\%. The bigger this factor, the more metallic impurity was removed.

Figure 10 shows that at a starting temperature of $680^{\circ} \mathrm{C}$, Nickel could be removed about $25 \%$, the highest reduction factor in this diagram. This factor is then reduced by increasing the starting temperature. The expected tendency (according to Figure 9) can be only seen in the case of Nickel, because Nickel's distribution coefficient is increasing with the temperature and that means that its removal should be impaired at higher temperature. According to Figure 9, Lead has the same effect as nickel. Their reduction factors, though, do not show the expected increasing tendency.

Application of the Burton-Prim-Slichter model (BPS): Figure 11 represents the implementation of the experimental values of $C_{S}$ and $C_{L}$ (via chemical analysis) as well as the empirical keff into the BPS model to calculate the experimental $k_{0}^{\prime}$. The preliminary results obtained showed a correlation of the $\delta / D$ coefficient in relation to impurities that has similar distribution coefficients. While the $k_{0}$ for iron and Silicon are 0.03 and 0.13 respectively, the obtained coefficients and $k_{0}^{\prime}$ were also close to each other. Same effect can be observed for the $\mathrm{Ni}$

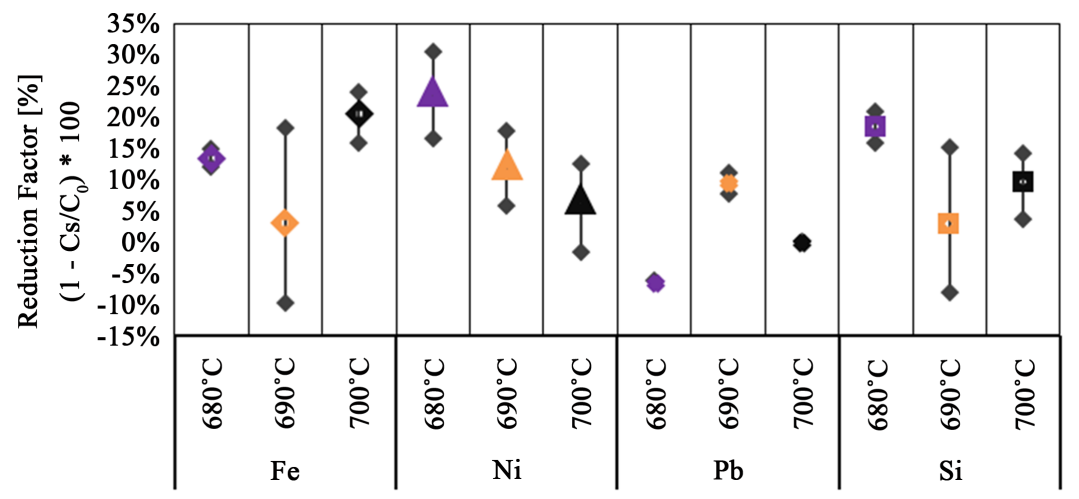

Figure 10. Comparison of the chemical analyses of Aluminum before and after "cooled finger" crystallization of different trials, calculated as reduction factor (\%). 

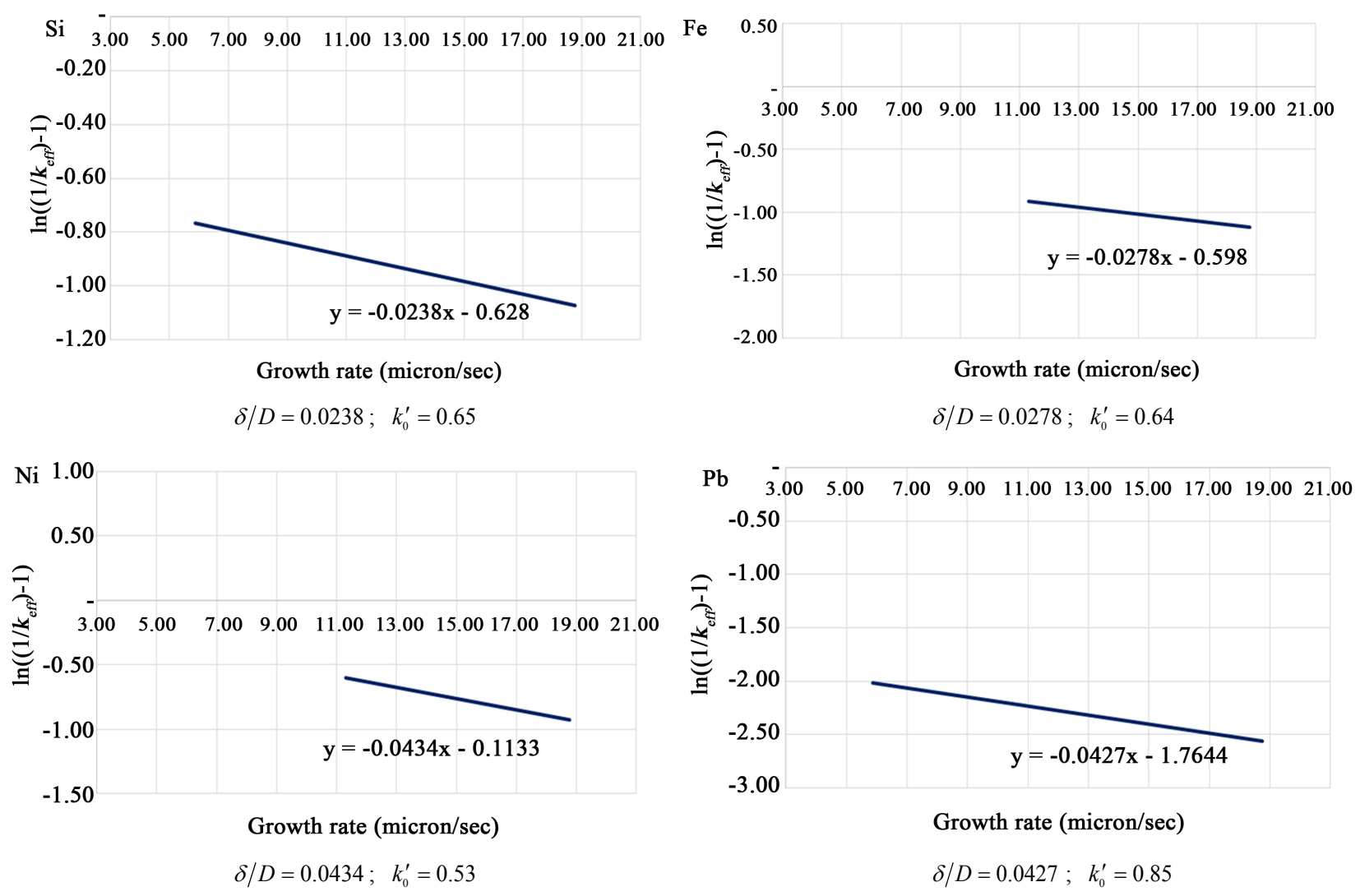

Figure 11. Implementation of the experimental values of $C_{S}$ and $C_{L}$ into the BPS model for Silicon, Iron, Nickel and Lead.

and $\mathrm{Pb}$ system. Despite the requirement of higher numbers of data in BPS model and despite the fact that in this series of experiments just few results exist for every measuring point, the graphs in Figure 10 illustrate an expected tendency. This confirms the validity of the empirical results at least for the binary systems investigated in this paper in correlation with the theoretical calculated values.

The difference between the thermodynamic distribution coefficients obtained from the binary phase diagram $\left(k_{0}\right)$ and the $k_{0}^{\prime}$ obtained by BPS method is related to the efficiency of the system, which must be improved for example by reducing the growth rate. That in turn will led to an increase in the overall purification efficiency, since more time is given to allow the segregation of impurities on the growth front. Rotation speed will also play an important role on promoting the mixing of the segregated impurities from the growth boundary layer to the bulk melt and hence on increasing the purification effectiveness. In the case of $\mathrm{Ni}$ and $\mathrm{Pb}$, the obtained $k_{0}^{\prime}$ was expected to be similar, as seen for Fe and $\mathrm{Si}$. This difference could indicate a correlation between the impurities present in the system with the $\mathrm{Pb}$ and/or $\mathrm{Ni}$.

\section{Conclusion and Outlook}

First time an internal cooled rotor was used for fractional crystallization. The study shows a successful proof of principle study in theory and experiments. Among the investigated cooling gas flow rates, the rate of $50 \mathrm{~L} / \mathrm{min}$ was shown 
to be the most suitable one both to avoid the mushy area in the melt as well as to avoid a rapid solidification of the material over the "cooled finger". Crystallization temperature was quite constant with $\pm 2{ }^{\circ} \mathrm{C}$ independent from the gas flow rate or the initial temperature of the melt. However, the chemical analysis' results of the different process parameters revealed to be significantly different.

The removal efficiencies of the impurities from aluminum via experimental investigation do not show always accordance to the calculated values of distribution coefficient in FactSage. That is due to the lack of taking the interaction of the accompanying elements into account. FactSage theoretical calculation applied in this study was based only on binary (e.g. Al-X), although the empirical investigations took place considering multi-component systems.

The graphs of BPS model were confirmed to be valid for binary systems Al-Si, $\mathrm{Al}-\mathrm{Ni}, \mathrm{Al}-\mathrm{Pb}$ and $\mathrm{Al}-\mathrm{Fe}$. An improved precision and better correlation between the BPS model and the theoretical values could be achieved through an increase in data points across a wide growth rate range, decreasing the influence of experimental uncertainties. Additionally, implementation of this model into a binary system would be beneficial to avoid the influence of accompanying elements in the overall purification results.

The solid-liquid interface shape plays an important role in the impurity distribution in the melt. It is expected that the boundary layer thickness can be further decreased by increasing the stirring (by rotation), and as consequence, decreases the $k_{\text {eff }}$ value and thereby maximizing the range of purification. The effect of rotation into the solute segregation shall be investigated in the future.

\section{Acknowledgements}

The Authors would like to appreciate Dr. Alexander Schwedt from GFE Central Facility for Electron Microscopy, RWTH Aachen University for the friendly supply of SEM/EDX analyses.

Also, many thanks to the CNPQ-Brazilian National Council for Scientific and Technological Development for the financial support of the Brazilian scholarship holder and guest researcher D. Curtolo.

\section{ORCID Numbers}

Dr.-Ing. Semiramis Friedrich: https://orcid.org/0000-0002-4078-0799; Danilo Coladetti Curtolo: https://orcid.org/0000-0002-7043-7094; Prof. Dr.-Ing. Dr. h.c. Bernd Friedrich: https://orcid.org/0000-0002-2934-2034.

\section{References}

[1] Scholz, R., Wangnick, K. and Ulrich, J. (1993) On the Distribution and Movement of Impurities in Crystalline Layers in Melt Crystallization Processes. Journal of Physics D: Applied Physics, 26, B156-B161.

[2] Trumbore, F.A., Isenberg, C.R. and Porbansky, E.M. (1958) On the Temperature-Dependence of the Distribution Coefficient: The Solid Solubilities of Tin in Silicon and Germanium. Journal of Physics and Chemistry of Solids, 9, 60-69. 
[3] Barthel, J., Buhirg, E., et al. (1982) Verlag für Grundstoffindustrie Leipzig. Kristallisation aus Schmelzen, 206-207.

[4] Prostomolotov, A.I., Verezub, N.A. and Voloshin, A.E. (2014) Simplified Numerical Approach for Estimation of Effective Segregation Coefficient at the Melt/Crystal Interface. Journal of Crystal Growth, 401, 111-115.

[5] Ulrich, J. and Glade, H. (2003) Melt Crystallization-Fundamentals, Equipment and Applications. Shaker.

[6] Kurz, W. and Fisher, D.J. (1989) Fundamentals of Solidification. Trans Tech Publications Ltd., Aedermannsdorf.

[7] Rudolph, P. and Nishinga, T. (2014) Handbook of Crystal Growth: Bulk Crystal Growth. Elsevier, Amsterdam, 389-397.

[8] Hurle, D.T.J. (1961) Constitutional Supercooling during Crystal Growth from Stirred Melts-I: Theoretical. Solid-State Electronics, 3, 37-44.

[9] Pfann, W.G. (1962) Zone Melting: This Technique Offers Unique Advantages in Purification and in Control of Composition in Various Substances. Science, 135, 1101-1109.

[10] Arai, K., Shingu, H., Sakaguchi, M., Nishide, T., Watanabe, O., Otsuka, R. and Tsukamoto, K. (1984) Process for Producing High-Purity Aluminum. US Patent No. 4469512 .

[11] Ostrogorsky, A.G. and Müller, G. (1992) A Model of Effective Segregation Coefficient, Accounting for Convection in the Solute Layer at the Growth Interface. Journal of Crystal Growth, 121, 587-598.

[12] Hu, S., Nozawa, J., Koizumi, H., Fujiwara, K. and Uda, S. (2015) Grain Boundary Segregation of Impurities during Polycrystalline Colloidal Crystallization. Crystal Growth and Design, 15, 5685-5692.

\section{Scientific Research Publishing}

Submit or recommend next manuscript to SCIRP and we will provide best service for you:

Accepting pre-submission inquiries through Email, Facebook, LinkedIn, Twitter, etc. A wide selection of journals (inclusive of 9 subjects, more than 200 journals)

Providing 24-hour high-quality service

User-friendly online submission system

Fair and swift peer-review system

Efficient typesetting and proofreading procedure

Display of the result of downloads and visits, as well as the number of cited articles

Maximum dissemination of your research work

Submit your manuscript at: http://papersubmission.scirp.org/

Or contact ojmetal@scirp.org 